\title{
Hybrid creatures as complicating visions of early childhood
}

\section{LINDA KNIGHT}

Queensland University of Technology (Australia)

HANNAH RAYNER

Payne Road State School (Australia)

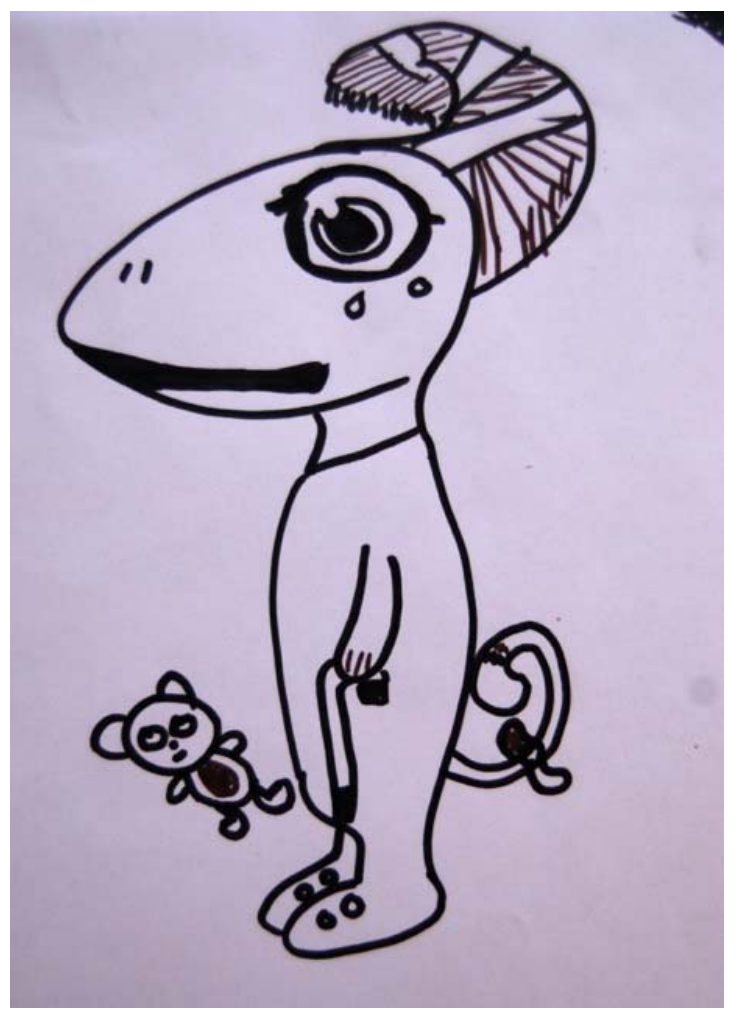

Complicity: An International Journal of Complexity and Education

Volume 12 (2015), Number $1 \bullet p p .86-97$ 
Our vignette features drawings produced by an adult and young child: my daughter and myself. The drawings are of hybrid beings, constructed from combinations of animal, human and creature. They float in isolation, without placement in any context or situation. Visually, the drawings manifest visions of complex beings that preoccupy and fascinate. They 'could' be human, they 'might' be animal; they 'probably' are creature.

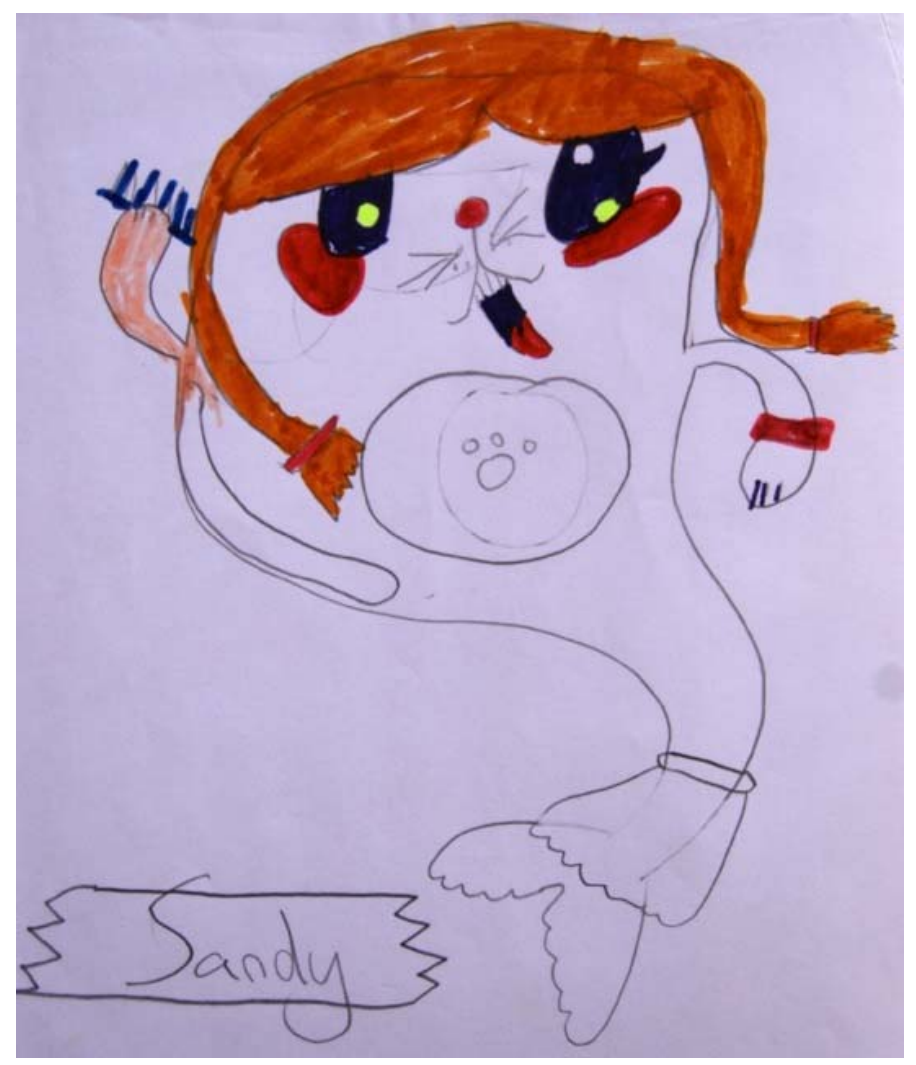

I noticed that Hannah created a lot of these hybrids, and for a while they became the sole subject matter of her drawings. Just a few are contained in this vignette, but there are many more.

I became fascinated with these creatures although I was not curious about extracting psychoanalytic meanings (such as trying to ascertain what certain combinations may infer or why particular hybrids are created). I did not try to interpret Hannah's drawings because I do not believe completed drawings can act as documents which tell a 'true' or accurate account of what happened in the past (as in, what occurred, what was thought about, what was decided upon, what the marks might reveal about growth and development). I regard drawings as a material consequence of an event, an event which has passed and therefore cannot be replicated or 'truly' accounted for. I did not attempt to conjure up the possible meanings of these completed drawings; I was interested in the 
possibilities they held for theorizing, researching and experimenting with concepts of hybridity, complexity, subjectivity and power.

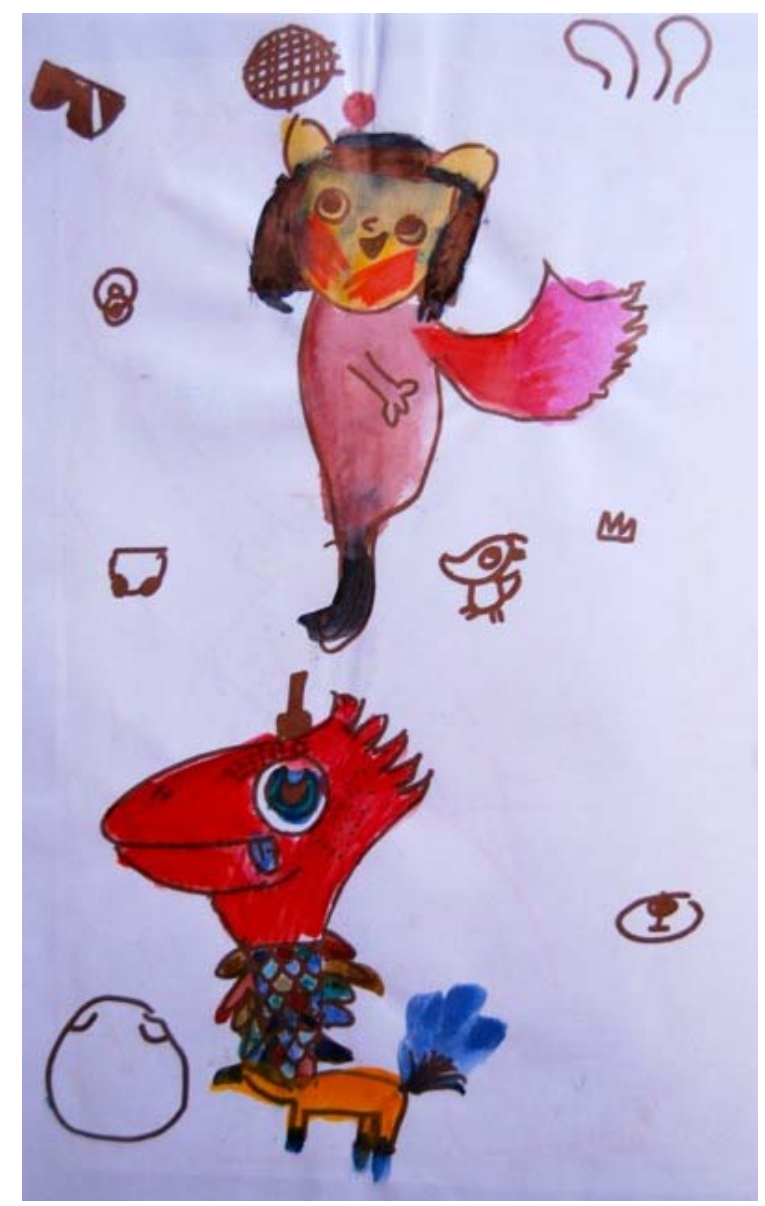




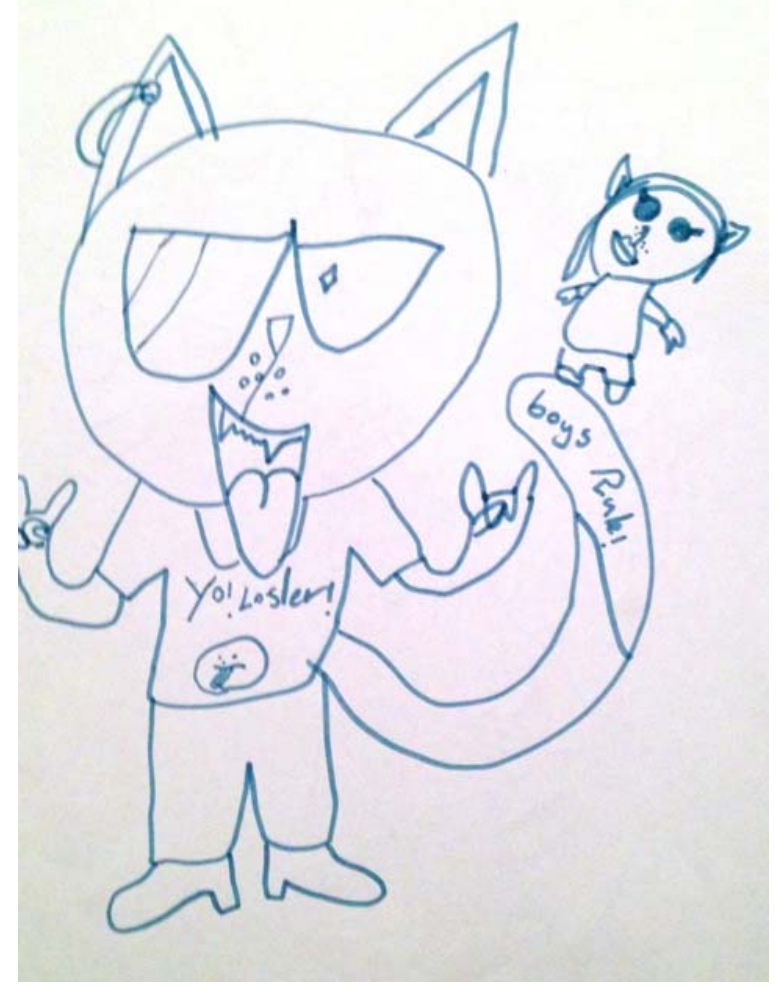

Hannah and I are listed as co-authors for this vignette to honor the ways we each experimented with becoming-other through complex entanglements of human, animal and creature, and our collaborative researching into these hybrids. We used visual means to carry our ideas into material objects, these graphic recordings offered us multiple trials for complicating, morphing and (trans)forming from our human selves to hybrid others, and pushing the biologic possibilities of 'being' beyond the singular 'child' subject.

Hannah drew alone initially. About a year after she began drawing the hybrids we decided to work together on creating beings, in part to continue our long-standing collaborative drawing relationship (we have drawn together since Hannah was eighteen months old - see Knight, 2008) but also to invite circumstances where our ideas, conversations, marks, concepts and subjectivities entangle, trouble and reconsider beings and how conventions for beings might be pushed, manipulated and contested. 







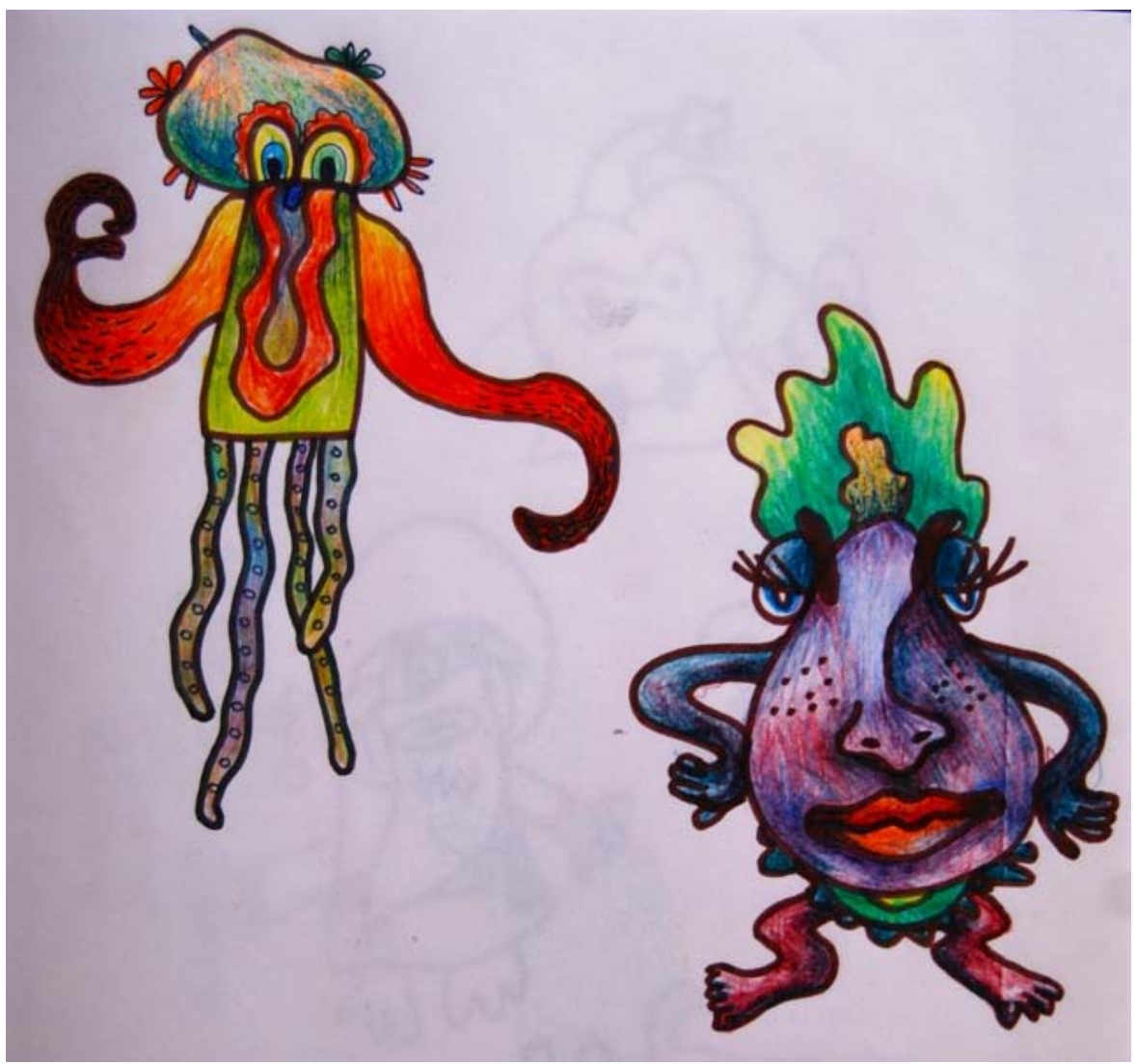

We worked together as arts based researchers (Barone \& Eisner, 2012), using a method that "addresses complex and often subtle interactions and that it provides an image of those interactions in ways that make them noticeable" (p. 3). Rather than analyzing the meanings of Hannah's solitary drawings then, or making field notes to describe her drawing procedures I understood that through searching around for visual materials, through experimenting with different human/animal/creature combinations, through thinking about the ways she could visually constitute a being on a piece of paper, Hannah was undertaking arts based research. I conducted arts based research by using the hybrid beings in her drawings as a type of 'data' to prompt me to think about childhood resistance to governance and control and how children can object to this hyper-management in conceptual ways: my observations of Hannah's initial drawings sharpened my ideas about hybridity and the complexities of childhood subjectivity which were carried forward into my subsequent visual and written activities. Collectively, we also held discussions about our images and these ideas then fed back into our subsequent collaborative, and solitary drawings. 

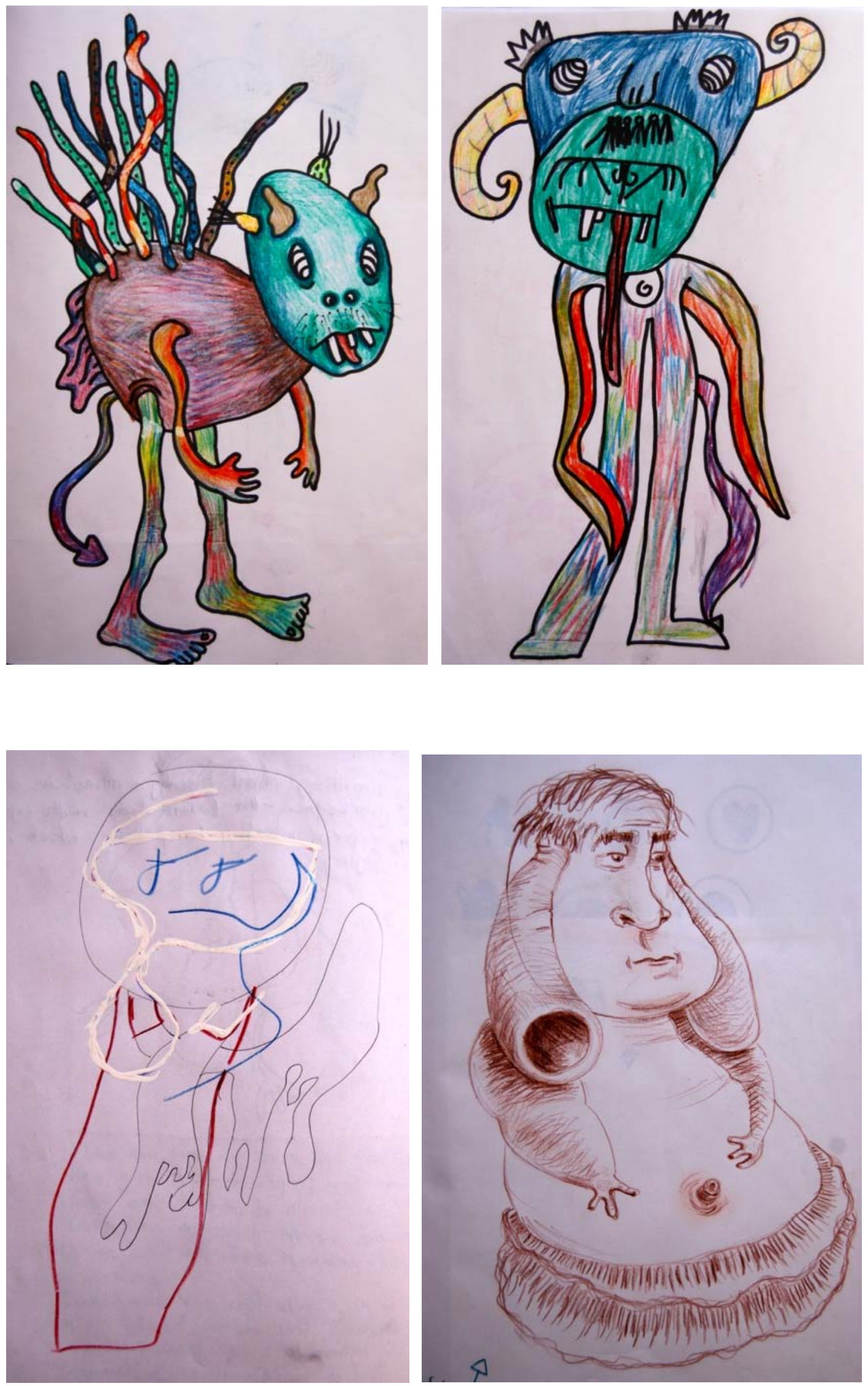
Hannah's drawings show how children can theorize on and subvert the conventions of what might realistically live on our planet. These beings are not fully fantasized monsters; they have aspects of human-ness that situate them in a becoming space, with a possibility to fully transform in any number of directions: human, animal, creature. It is this becoming, this potentiality which makes these beings interesting. By creating hybrid beings that are 'not-quite', children can contemplate subjectivities, identities, conventionalities and their relationships to/fantasies about these. Our hybrid drawings offer entryways into thinking about young children in more complicated ways than the early childhood discourses that populate and become mainstreamed in academic and professional early childhood discourses.
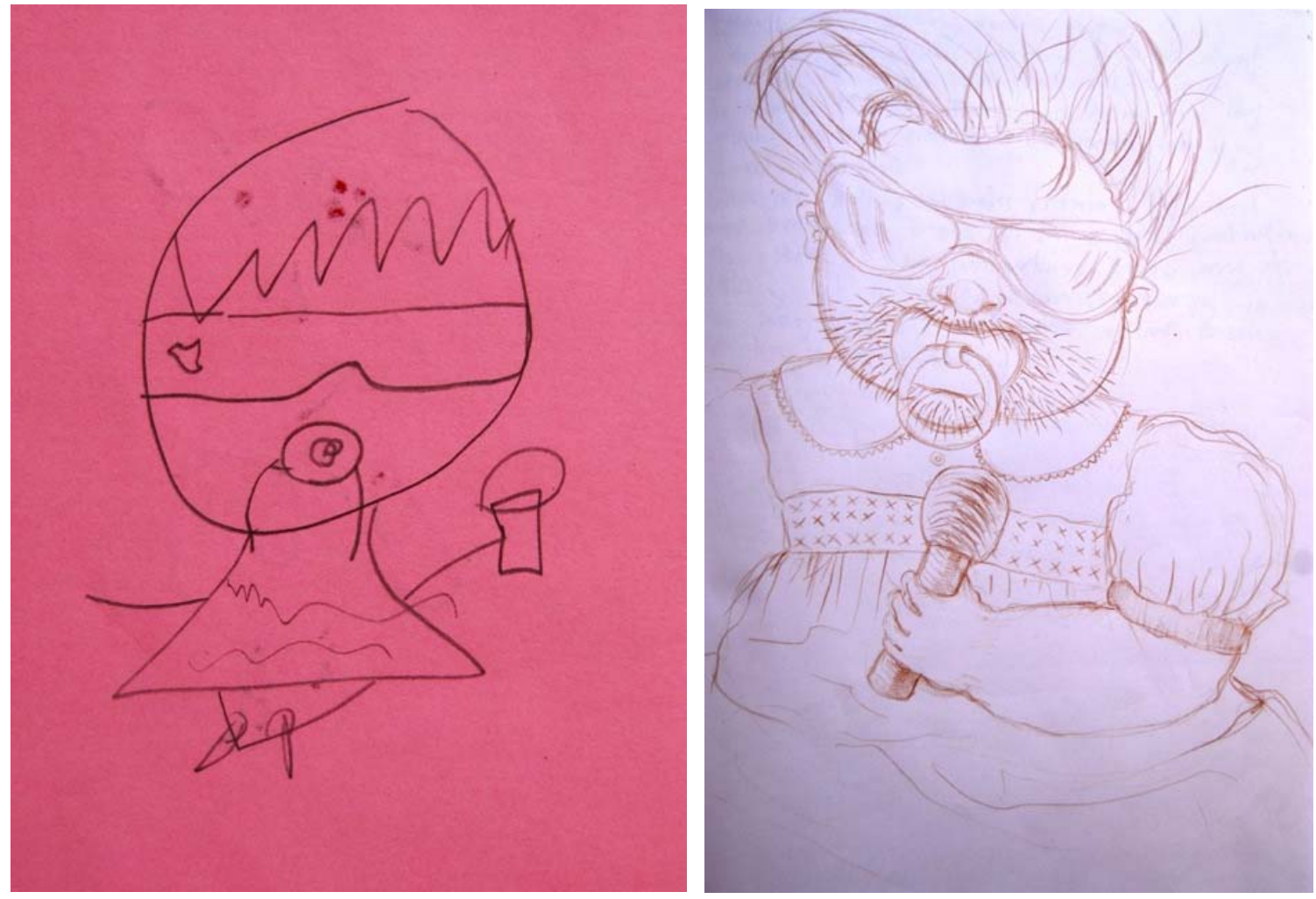

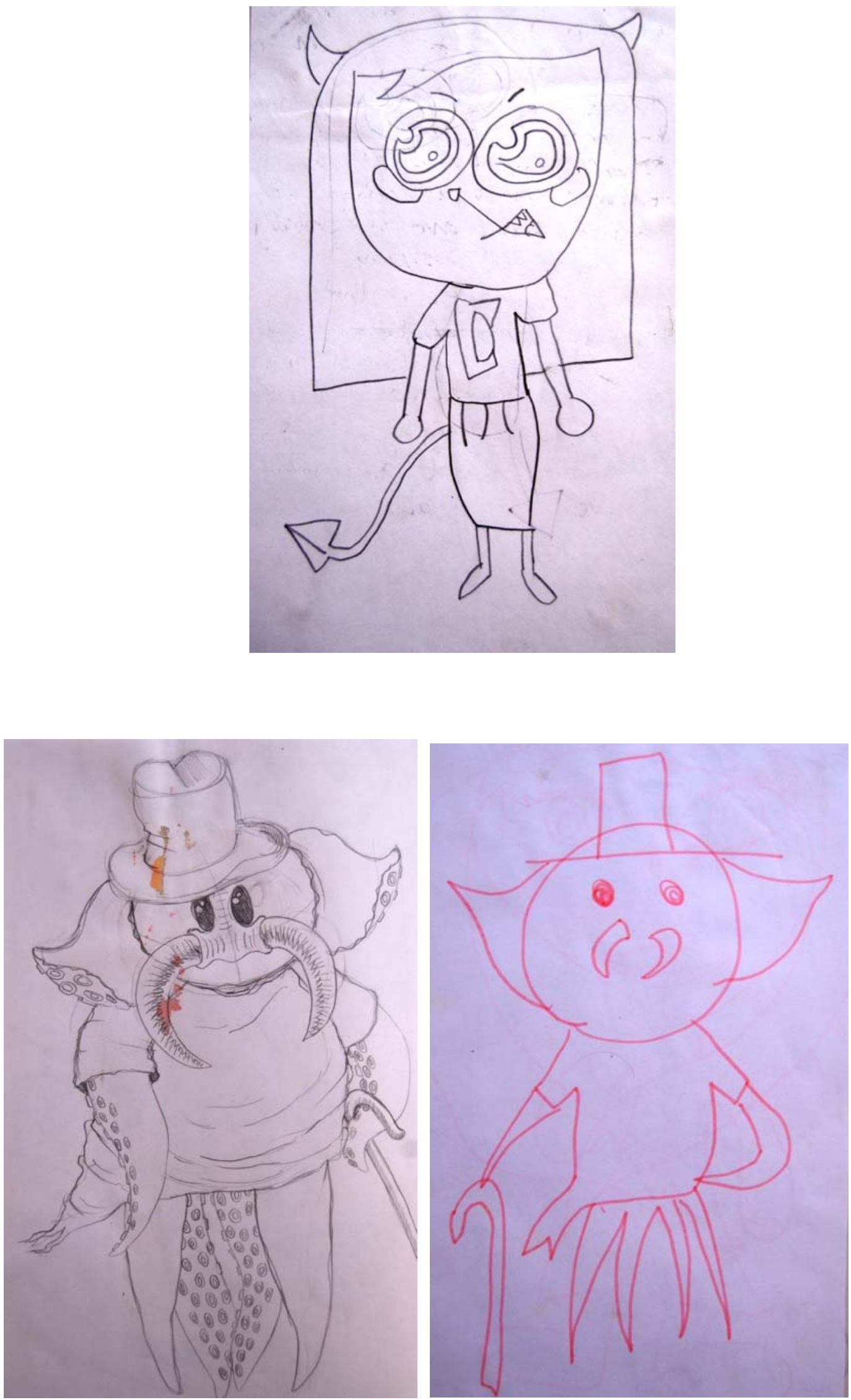

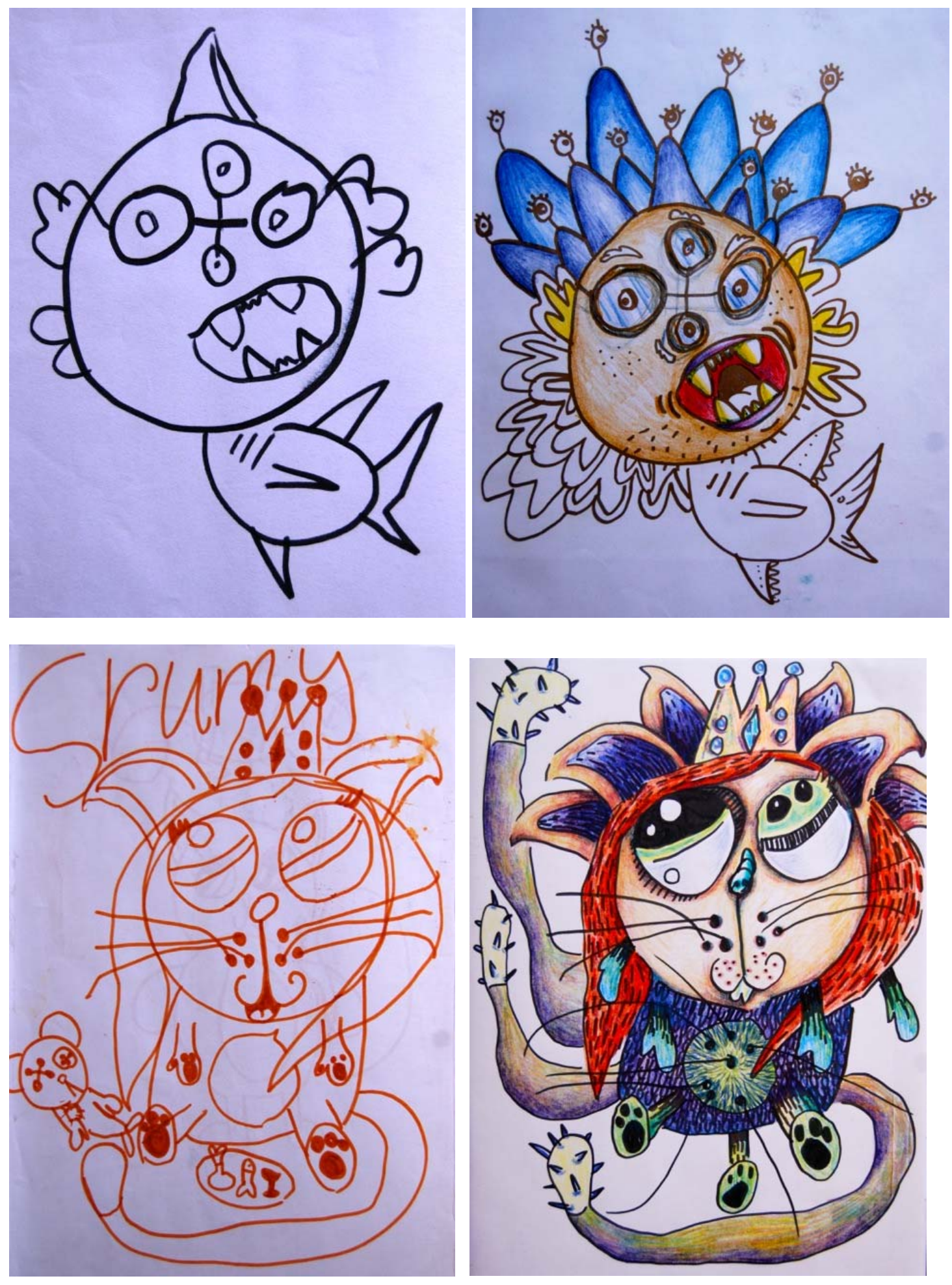

The beings that feature in our drawings are indeterminate and irregular and would be incredibly difficult to try and construct in other, more discursive or literary ways. As an artifact these drawings can hold many subtleties that are often lost or never surface at all 
if written about or orally described: the morphed, hybridized imaginings seen in these drawings therefore actively help force interrogations of theories of childhood about complexity, plurality, and subservience in early childhood. More than that however, these drawings are important research artifacts, which help to assert drawing as an intellectual, academic modality.

Declaring drawing as a serious 'multiliteracy' however challenges well-established research (discursive) conventions in professional and academic early childhood spaces because drawing is regarded by many as mysterious, artistic, something long-lost from their own childhood (and thus child-like).

To hold such a view is a form of intellectual blindness: when first meeting and working with Gurindji Elders, who connect, collect and recollect history in particular ways, Hokari (2011), in thinking about knowledges, subjectifications and truths, interrogated his personal assumptions about the definitions, recordings and orderings of history he had come to think of as unshakeable and 'true'. He asked "are academic systems of knowledge really so unshakeably superior?" (p. 39). Hokari's prior westernized, academic understandings of 'History' were dislodged by his encounter with different ways of being with the world, and his realization was that history cannot be conceptualized simply. His understandings had been complicated by "..the plurality of history, the multiplicity of voices, ...hybridity, ambivalence, subalternity" (p. 39).

Just as Hokari (2011) had come to understand history through a series of particular discourses that excluded 'othered' Indigenous discourses, the assumptive knowledges, subjectifications and truths that are held about young children in early childhood professional and academic systems can, likewise, effectively shroud the ways children can be acted upon, subjectified, simplified, shaped, governed, regulated, and 'manufactured'. Even if adults consider themselves early childhood 'experts', they may not be open to the different ways for being with children, and thus not open to the complex ways children are with the world.

Hannah used drawing as a 'way' for investigating concepts around subjectivities. Making images enabled Hannah to subtly experiment with her ideas and imaginings and to explore her curiosity of the possibilities of becoming-hybrid. Making drawings allowed Hannah to wander away from herself as a mainstreamed child subject, shaped by commercialization, policy, education, culture, history. While collectively, Hannah and I were able to wonder about the possibilities of 'being' with subtlety, humour and curiosity, creating hybrids through drawing helped each of us to reconceptualize and complicate our mainstreamed visions of childhood.

\section{References}

Barone, T. \& Eisner, E.W. (2012) Arts Based Research. Los Angeles: Sage.

Hokari, M. (2011). Gurindji Journey: a Japanese historian in the outback. Honolulu: University of Hawai'i Press.

Knight, L. (2008). Communication and Transformation Through Collaboration: rethinking drawing activities in early childhood. Contemporary Issues in Early Childhood, 9(4), 307 - 316. 


\section{Acknowledgments}

I would like to thank my co-author and daughter, Hannah, for her enthusiasm and imagination and for her willingness to collaborate on this project. This paper was originally presented as 'Hybrid creatures as complicating visions of early childhood.' Honoring the Child, Honoring Equity 14, Embracing Diverse Identities, University of Melbourne, 21-22 November 2014.

\section{About the Author/s}

Linda Knight is a Senior Lecturer in Early Childhood, Queensland University of Technology, Australia, and Research Director, Art Education Australia. Linda is interested in postqualitative inquiry, Deleuzian and Guattarian theories in relation to education, and art as a critical and pedagogic act. Linda is an international artist, exhibiting in Australia, New Zealand, USA and UK and her work is held in private collections in USA, UK, and Australia. Linda.knight@qut.edu.au http://lindaknight3.wix.com/femdemics

Hannah is in year 5 at school, she is very interested in art, and loves to draw all the time. Hannah also enjoys drawing with Linda and has exhibited these drawings in Canberra, Australia. Hannah also likes computer games, particularly art games. Hannah's idol is Katniss Everdeen.

(c) Copyright 2015. The authors, LINDA KNIGHT and HANNAH RAYNER, assign to the University of Alberta and other educational and non-profit institutions a non-exclusive license to use this document for personal use and in courses of instruction provided that the article is used in full and this copyright statement is reproduced. The authors also grant a non-exclusive license to the University of Alberta to publish this document in full on the World Wide Web, and for the document to be published on mirrors on the World Wide Web. Any other usage is prohibited without the express permission of the authors. 